\title{
HYDROXYUREA IN THALASSEMIA MAJOR
}

\author{
Alka Yadav1, Pankaj Abrol2, Sunita Singh ${ }^{3}$, Maha Singh4, Sanjeev Nanda 5
}

${ }^{1}$ Assistant Professor, Department of Paediatrics, Pt. B. D. Sharma PGIMS, Rohtak.

${ }^{2}$ Senior Professor, Department of Paediatrics, Pt. B. D. Sharma PGIMS, Rohtak.

${ }^{3}$ Professor, Department of Pathology, Pt. B. D. Sharma PGIMS, Rohtak.

${ }^{4}$ Assistant Professor, Department of Paediatrics, Pt. B. D. Sharma PGIMS, Rohtak.

${ }^{5}$ Senior Professor, Department of Paediatrics, Pt. B. D. Sharma PGIMS, Rohtak.

\section{ABSTRACT}

\section{BACKGROUND}

Hydroxyurea (HU) is found to be effective in sickle cell anemia and thalassemia intermedia. Its usefulness in thalassemia major is not clearly defined. The aim of the study was to analyze effectiveness of hydroxyurea in children with beta thalassemia major.

\section{PARTICIPANTS}

Patients of thalassemia major aged 3 years to 18 years, on regular blood transfusion with proper chelation for at least two years and in spite of that they were not able to maintain their pre-transfusion hemoglobin level of at least 8.0 gm\% were selected as cases. Parameters understudy of these patients observed six months prior to the beginning of the study were considered as controls.

Hydroxyurea (the study drug) was given at an average dose of $13.70 \pm 2.80 \mathrm{mg} / \mathrm{kg} / \mathrm{d}$ as single oral dose to all cases for one year.

\section{RESULTS}

Twenty five children were enrolled for present study. Fourteen (56\%) and 23 (92\%) patients out of 25 children showed response to $\mathrm{HU}$ therapy when change in hemoglobin $(\mathrm{Hb})$ and mean fetal hemoglobin level $(\mathrm{HbF})$ levels were taken as response criteria respectively. Out of those, 7 children (28\%) showed more than $10 \%$ (good response) rise in mean hemoglobin level while 10 (40\%), $6(24 \%)$ and $2(8 \%)$ patients showed moderate (5-10\%), mild response $(<5 \%)$ and no response $(0 \%)$ respectively to HU. Hydroxyurea significantly increases fetal hemoglobin levels and total hemoglobin after a duration of 3 months and 6 months respectively. There was also a statistically significant increase in the interval between the transfusions from a mean of 19.8 (13$30) \pm 4.038$ days to $21.68 \pm 4.413$ days at 6 months and $25.76(18-42) \pm 6.629$ days at 12 months during the study. Over study period serum ferritin levels decreased though insignificant in all the cases from $3^{\text {rd }}$ month onwards. No significant side effects were noted at the dose used in study.

\section{CONCLUSIONS}

Hydroxyurea can be used for the treatment of transfusion dependent thalassemia patients as an effective adjunct to regular transfusion regimen and cost and side effects can be reduced significantly.

\section{KEYWORDS}

Fetal Hemoglobin Augmentation, Hydroxyurea, Pharmacotherapy Thalassemia Major.

HOW TO CITE THIS ARTICLE: Yadav A, Abrol P, Singh S, et al. Hydroxyurea in thalassemia major. J Evolution Med Dent Sci 2016; 5(5):287-291, DOI: 10.14260/jemds/2016/62

\section{INTRODUCTION}

Beta thalassemia is the most common single gene disorder in the world. Worldwide prevalence of gene varies between118\% (Mean 9.5\%) while in India its between 1-7\% (Mean $3.3 \%)^{1} \quad$ Nearly 8000 to 10,000 new thalassemics (Homozygous) are born every year in India. ${ }^{2}$ Over the past three decades, regular blood transfusions and iron chelation has dramatically improved the quality of life and has transformed the thalassaemia from a rapidly fatal disease in early childhood to a chronic disease compatible with prolonged life. Today life expectancy varies between 25-55 years, depending on the compliance with medical treatment.

Financial or Other, Competing Interest: None.

Submission 05-01-2016, Peer Review 06-01-2016,

Acceptance 11-01-2016, Published 18-01-2016.

Corresponding Author:

Dr. Alka Yadav,

H. No. $48 / 11$,

Medical Campus

Rohtak-124001.

E-mail:alkadv9@gmail.com

DOI:10.14260/jemds/2016/62
Despite increased life expectancy, complications keep arising. These relate to inadequate transfusions, transfusionrelated infections, all sensitization, iron-overload related cardiac, endocrine and liver disturbances and toxicities of iron chelators. $^{3}$ Limited supply of blood and risk of transfusiontransmitted viral infections especially in resource depleted countries like India prompted researchers to look for alternative approaches to manage beta-thalassemia. Hemoglobin $\mathrm{F}(\mathrm{HbF})$ augmentation using pharmacological and non-pharmacological methods is one such concept; if gammaglobin gene can be reactivated in postnatal life, then gammaglobin chain synthesis will restart.

This will reduce the imbalance of alpha-beta/no alpha globin chain ratio in red cells and ameliorate the biochemical defects in hemoglobin molecule and partially correct the ineffective erythropoiesis. ${ }^{4}$ Hydroxyurea has been used successfully in the treatment of sickle cell anemia and thalassemia minor as reported by various authors, although there is limited experience with this agent in beta thalassemia major patients. ${ }^{5-7}$ 
Based on the same knowledge we conducted the present study with Hydroxyurea as the study drug and to observe whether its use can decrease packed red cells transfusions in thalassemia major patients.

\section{METHODS}

\section{Study Design}

Prospective case-control study.

\section{Setting}

Thalassemia day care center of a tertiary health care center of North India.

\section{Patients}

This study was conducted over a period of one year (August 2008 - September 2009) at Thalassemia day care center in the Department of Pediatrics at a Tertiary Care Teaching Institute of North India. Twenty five patients of thalassemia major aged 3 years to 18 years registered at the thalassemia day care center of the institute, who were on at least 2 years of regular blood transfusion with proper chelation despite that they were not able to maintain their pre-transfusion hemoglobin level of at least $8.0 \mathrm{gm} \%$ were selected as cases.

\section{Exclusion Criteria}

Patients with renal or liver disease or on interferon/cancer therapy were not enrolled for the study. Children who could not be followed up and in whom compliance could not be assured were also not included.

\section{Controls}

Cases selected for the study also acted as control for comparison of various parameters in the study. Transfusion requirements during 6 months preceding the study were taken as control.

\section{Intervention}

The patients were given hydroxyurea $10-20 \mathrm{mg} / \mathrm{kg} /$ day as a single dose (To nearest $250 \mathrm{mg}$ capsule). Hydroxyurea was available in market in 500mg capsules only, so the drug was re-dispensed in $250 \mathrm{mg}$ capsules under all aseptic precautions in the pharmacy department of the institute. ${ }^{8}$ All patients also received concurrent folic acid and calcium supplementation.

\section{Follow-up}

A detailed history and physical examination including age of presentation, age at diagnosis, history of consanguinity of parents, weight and other relevant details were recorded at the time of enrollment. HIV, HBsAg, HCV status, complete hemogram with absolute platelet count, liver function tests (SGOT/SGPT, serum alkaline phosphatase), renal function tests (Blood urea, serum creatinine), fetal hemoglobin (HbF) and serum ferritin levels were evaluated at the time of enrollment and then repeated at monthly interval for initial 3 months and 3 monthly thereafter for one year. Patients continued to get regular blood transfusion along with chelation therapy during follow-up period. If during the visit pre-transfusion hemoglobin was recorded to be more than $10.0 \mathrm{gm} / \mathrm{dL}$, blood transfusion was withheld for next one week and patient called for followup. On followup visit again transfusion was decided on the basis of pre-transfusion hemoglobin.
Response to hydroxyurea therapy at the end of study was arbitrarily categorized as marked ( $>10 \%)$, moderate (5-10\%), mild $(0-5 \%)$ increase in mean hemoglobin level from the baseline value.

\section{Side Effects}

Hematological toxicity was defined by Absolute Neutrophil Count (ANC) less than $1.5 \times 10^{9} / 1$ or platelet count less than $100 \times 10^{9} / 1$. Non-hematological side effects like skin pigmentation, facial erythema, maculopapular rash, nail abnormalities and gastrointestinal side effects were noted if any.

\section{STATISTICAL ANALYSIS}

Records of amount and frequency of blood transfusion were evaluated over one year of therapy and compared with control values using paired - T tests and correlation tests using SSPS version 15 . $\mathrm{P}$ values of less than 0.05 were considered statistically significant.

\section{RESULTS}

Twenty five patients, 17 (68\%) male and 8 (32\%) female fulfil the inclusion criteria at enrolment and received the study drug. None of patients dropped out of the study during the stipulated time. Hydroxyurea (The study drug) was given to all patients for the period of one year at an average dose of $13.70 \pm 2.80 \mathrm{mg} / \mathrm{kg} / \mathrm{d}$ as a single oral dose.

We observed a statistically significant decrease in the number of transfusions during the hydroxyurea therapy. The average number of transfusions per year before enrollment in the study was $11.7 \pm 2.807$, while after completion of one year study period were $9.5 \pm 3.020$. We also observed a statistically significant increase in the interval between the transfusions during the study from a mean of $19.8(13-30) \pm 4.038$ days to $21.68 \pm 4.413$ days at 6 months and $25.76(18-42) \pm 6.629$ days at 12 months (Table I). Though none of our patients became transfusion independent, transfusions can be suspended for about 4-15 days.

The mean age $\pm \mathrm{SD}$ of the subjects at the time of diagnosis was $18.36 \pm 14.80$ months, while the age at the time of enrollment in the study was $11.7 \pm 3.95$ years. All patients were on chelation treatment for a mean duration of $7.9 \pm 3.58$ years. Chelation regime followed were highly variable among the study subjects, depending upon the affordability and acceptability. Fourteen (56\%) patients were on oral deferiprone, $4(16 \%)$ on desferrioxamine and $2(8 \%)$ were on the new oral chelator deferasirox and $5(20 \%)$ patients were on combined chelation therapy of deferiprone and desferrioxamine. The baseline epidemiological characteristics of the patients were as shown in Table II.

A consistent and progressive increase in the hemoglobin was observed throughout the study after 6 months of therapy ( $p$ <0.05). The mean hemoglobin level at the time of enrollment in the study was $6.648 \mathrm{gm} / \mathrm{dl}$, ranged between 5.8 to $7.6 \mathrm{mg} / \mathrm{dl}$. The mean hemoglobin level in the preceding 6 months to the study was $6.652 \pm 0.563 \mathrm{gm} / \mathrm{dl}$ (Range 5.6$7.6 \mathrm{gm} / \mathrm{dl}$ ). The mean hemoglobin levels at 6 months, 9 months and 1 year of study were $6.920 \pm 0.547 \mathrm{gm} / \mathrm{dl}$, $6.940 \pm 0.614 \mathrm{gm} / \mathrm{dl}$ and $7.068 \pm 0.696 \mathrm{gm} / \mathrm{dl}$ respectively (Table 3). The increment was statistically significant that means hydroxyurea does not lose efficacy. Patients on hydroxyurea did not develop tolerance to it. 
At the end of the study only 7 patients (28\%) showed a marked response in mean $\mathrm{Hb}(>10 \%$ rise) in while 10 (40\%) patients, $6(24 \%)$ patients and $2(8 \%)$ patients showed moderate $(5-10 \%)$, mild response $(<5 \%)$ and no response $(0 \%)$ respectively to $\mathrm{HU}$ in the present study.

The mean fetal hemoglobin level $(\mathrm{HbF})$ at the time of enrolment in the study was $61.84 \pm 11.974 \%$ (Range $40-85 \%$ ). The mean value in the preceding 6 months of the study was $62.20 \pm 11.365$ (Range 47-83\%). At 3 months, the mean $\mathrm{HbF}$ level increased to $63.88 \pm 14.469 \%$ and this increase was statistically significant when compared with the control value. The mean fetal hemoglobin HbF levels at 6 months, 9 months and 1 year of study were $66.84 \pm 14.105,69.20 \pm 14.488$ and $72.52 \pm 14.804 \%$ respectively. A statistically significant increase was observed when these values were compared with the value of the mean hemoglobin level at 6 months prior to the study $(\mathrm{p}<0.05)$. Following HU therapy $3(12 \%)$ patients showed marked (40-60\% rise in HbF level), 11 (44\%) patients moderate $(20-40 \%)$ and $11(44 \%)$ patients showed mild responses $(<20 \%)$ (Table III).
The mean value of serum ferritin in our patients at the time of enrollment to the study was $4701.232 \pm 2943.63 \mathrm{ng} / \mathrm{dl}$.

The ferritin level served as control in to the study was $4851.272 \pm 3142.79 \mathrm{ng} / \mathrm{dl}$. Over one year of study period serum ferritin levels decreased significantly in all the cases from $3^{\text {rd }}$ month onwards. The observed means were $4636.09 \pm 2853.11$, $4475.25 \pm 2627.22, \quad 4405.18 \pm 2608.75$ and $4265.34 \pm 2427.77 \mathrm{ng} / \mathrm{dl}$ at $3^{\text {rd }}, 6^{\text {th }}, 9^{\text {th }}$ and $12^{\text {th }}$ month of therapy respectively (Table IV).

No significant difference was noted among patients in terms of sex distribution, age at last follow up, age at first transfusion, time taken to reach maximum hemoglobin, starting dose of HU and duration of HU therapy. Only three patients (12\%) suffered the side effects of hydroxyurea during present study. Out of them two (8\%) patients developed temporary thrombocytopenia one after 3 months and another after 9 months of therapy and one patient (4\%) developed gastritis during $5^{\text {th }}$ month of therapy.

\begin{tabular}{|c|c|c|c|c|c|c|}
\hline \multirow[b]{2}{*}{ Time } & \multicolumn{3}{|c|}{ Mean Hemoglobin Levels } & \multicolumn{3}{|c|}{ Mean HbF Levels } \\
\hline & $\begin{array}{c}\text { Mean } \pm S D \\
(\mathrm{gm} / \mathrm{dL})\end{array}$ & Range & $P$ value & $\begin{array}{c}\text { Mean } \pm \text { SD } \\
(\mathrm{gm} / \mathrm{dL})\end{array}$ & Range & P value \\
\hline $\begin{array}{l}\text { In } 6 \text { months prior } \\
\text { to the study } \\
\text { (control) }\end{array}$ & $6.652 \pm 0.563$ & $5.6-7.6$ & - & $62.20 \pm 11.365$ & $47-83$ & - \\
\hline At enrollment & $6.648 \pm 0.635$ & $5.8-7.6$ & $>0.05$ & $61.84 \pm 11.974$ & $40-85$ & $>0.05$ \\
\hline At 1 month & $6.656 \pm 0.534$ & $5.8-7.6$ & $>0.05$ & $61.94 \pm 11.967$ & $38-85$ & $>0.05$ \\
\hline At 2 months & $6.713 \pm 0.514$ & $6.0-7.8$ & $>0.05$ & $62.43 \pm 12.034$ & $37-87$ & $>0.05$ \\
\hline At 3 months & $6.728 \pm 0.596$ & $6.0-8.0$ & $>0.05$ & $63.88 \pm 14.469$ & $30-89$ & $<0.05$ \\
\hline At 6 months & $6.920 \pm 0.547$ & $6.0-8.2$ & $<0.05$ & $66.84 \pm 14.105$ & $34-92$ & $<0.05$ \\
\hline At 9 months & $6.940 \pm 0.614$ & $6.0-8.2$ & $<0.05$ & $69.20 \pm 14.488$ & $36-94$ & $<0.05$ \\
\hline At 12 months & $7.068 \pm 0.696$ & $6.2-8.2$ & $<0.005$ & $72.52 \pm 14.804$ & $40-95$ & $<0.05$ \\
\hline
\end{tabular}

\begin{tabular}{|c|c|c|}
\hline & Mean \pm Standard Deviation (SD) & Range \\
\hline Age at enrollment (years) & $11.7 \pm 3.95$ & $13-45$ \\
\hline Weight (kgs) & $26.62 \pm 8.97$ & $99-154$ \\
\hline Height (cms) & $125.72 \pm 14.03$ & $7-72$ \\
\hline $\begin{array}{c}\text { Mean age at } \\
\text { diagnosis (Months) }\end{array}$ & $18.36 \pm 14.80$ & $3.5-14$ \\
\hline Duration of chelation therapy (years) & $7.9 \pm 3.58$ & - \\
\hline No. of Patients with splenectomy & $3(12 \%)$ & $3-6.3$ \\
\hline $\begin{array}{c}\text { Spleen size at time of enrollment (cms) } \\
\text { n=22 }\end{array}$ & $4.52 \pm 0.84$ & $10.2-19.5$ \\
\hline \multicolumn{2}{|c|}{} \\
\hline \multicolumn{2}{|c|}{ Table 2: Baseline epidemiological profile of the study subjects at enrolment } \\
\hline
\end{tabular}

\begin{tabular}{|c|c|c|c|c|c|c|}
\hline \multirow{2}{*}{ Time } & \multicolumn{2}{|c|}{ Number of Transfusions } & \multicolumn{2}{c|}{$\begin{array}{c}\text { Average Intervals between } \\
\text { Transfusions (days) }\end{array}$} \\
\cline { 2 - 7 } & Mean + SD & Range & $\begin{array}{c}\text { p- } \\
\text { value }\end{array}$ & $\begin{array}{c}\text { Mean } \pm \text { SD } \\
\text { (days) }\end{array}$ & $\begin{array}{c}\text { Range } \\
\text { (days) }\end{array}$ & $\begin{array}{c}\text { p- } \\
\text { value }\end{array}$ \\
\hline $\begin{array}{c}\text { At enrolment } \\
\text { (Mean of the } \\
\text { findings in 6 } \\
\text { months prior to } \\
\text { the study) }\end{array}$ & $11.7 \pm 2.807$ & $6.8-17.4$ & - & $19.84 \pm 4.038$ & $13-30$ & - \\
\hline $\begin{array}{c}\text { At 6 months of the } \\
\text { study }\end{array}$ & $10.68 \pm 2.544$ & $6.0-16.8$ & $>0.05$ & $21.68 \pm 4.413$ & $15-30$ & $<0.005$ \\
\hline $\begin{array}{c}\text { At 12 months } \\
\text { (Adjusted for } \\
\text { controls) }\end{array}$ & $9.5 \pm 3.020$ & $4.9-15.7$ & $\begin{array}{c}0.0005 \\
(<0.05)\end{array}$ & $25.76 \pm 6.629$ & $18-42$ & $<0.005$ \\
\hline \multicolumn{7}{|c|}{ Table 3: Comparative analysis of transfusion requirement } \\
variables pre and post hydroxyurea therapy
\end{tabular}




\begin{tabular}{|c|c|c|c|}
\hline Time & $\begin{array}{c}\text { Mean } \pm \text { Standard Deviation } \\
(\mathbf{m g} / \mathbf{d l})\end{array}$ & Range & P value \\
\hline Control value & $4851.27 \pm 3142.79$ & $987.0-12000.0$ & - \\
\hline At enrolment & $4701.23 \pm 2943.63$ & $982.0-12784.2$ & 0.189 \\
\hline At 3 months & $4636.09 \pm 2853.11$ & $978.6-11890.3$ & 0.029 \\
\hline At 6 months & $4475.25 \pm 2627.22$ & $1134.7-10435.7$ & 0.014 \\
\hline At 9 months & $4405.18 \pm 2608.75$ & $1045.7-9576.8$ & 0.003 \\
\hline At 12 months & $4265.34 \pm 2427.77$ & $956.8-10387.8$ & 0.005 \\
\hline \multicolumn{2}{|r|}{ Table 4: Comparative analysis of serum ferritin levels pre and post hydroxyurea therapy } \\
\hline
\end{tabular}

\section{DISCUSSION}

We described responses of 25 transfusion-dependent major beta thalassemic patients with the treatment of HU. The effects on total $\mathrm{Hb}$, transfusion requirements, and the level of ferritin were the most significant observation of our study. The mainstay of treatment in major $\beta$-thalassemia is regular blood transfusion and the use of iron chelators. Pharmacologic reactivation of $\gamma$-globin genes using drugs, for example hydroxyurea holds great promise for the treatment of thalassemia syndromes as well as of sickle cell disease.9-12

In present study dose of hydroxyurea chosen was 10 $20 \mathrm{mg} / \mathrm{kg} / \mathrm{d}$. Earlier studies on use of hydroxyurea favours this dose range. ${ }^{13,14}$ Hoppe C. et al. found prolonged responses as determined by increases in total $\mathrm{Hb}$ and decreased transfusion needs were achieved with low doses of $\mathrm{HU}(3-10 \mathrm{mg} / \mathrm{kg} /$ day) in thalassemia major patients. However, higher doses were associated with mild reversible hematologic or hepatic toxicity and no further increase in hemoglobin. ${ }^{15}$

We observed a significant decrease in blood transfusion requirement beginning in the first three to four months of $\mathrm{HU}$ therapy. Similar findings were reported by Bradi et al. and Zamani F et al. who evaluated the long-term efficacy and safety of hydroxyurea in major beta-thalassemic patients and observed substantial and persistent increase in total hemoglobin levels after first three and four months of hydroxyurea therapy respectively.7,16 Fucharosen S. et al. observed hematologic effects of orally administered HU in 13 patients with beta thalassemia major/HbE. Almost all patients responded to oral dose of $\mathrm{HU}(10-20 \mathrm{mg} / \mathrm{kg} / \mathrm{d})$ for 5 months with a slight $(10 \%)$, but statistically significant increase in hemoglobin levels and an improved balance in $\alpha$ : non- $\alpha$ globin chain ratios. ${ }^{17}$ In the present study none of our patients became transfusion independent, though duration between transfusions was significantly increased (Over up to 42 days in one patient). The failure to make any of the patient transfusion free could be due to short span of therapy. Sachdeva A. et al. observed that $25 / 70(36 \%)$ patients had a complete response as need for transfusion was obviated, 15/70 (21\%) patients had a partial response as the interval between transfusions increased to $\mathrm{HU}$ therapy (Dose of $15-20 \mathrm{mg} / \mathrm{kg} /$ day for a period of 4 months to 3 years). ${ }^{18}$ Bradai M. et al. reported a marked elevation of total $\mathrm{Hb}$ levels with $\mathrm{HU}$ that permitted regular transfusions to be stopped in 7 children with transfusion-dependent $\beta$-thalassemia. ${ }^{19}$ The significant decrease of serum ferritin observed in our patients is clinically very important as iron overload is the main hazard to these patients. The serum ferritin decrement is due to decrease of blood transfusion and to a lesser extent due to increased iron utilization by increased $\mathrm{Hb}$ production and also suppression of ineffective erythropoiesis.

HU treatment was well-tolerated and it did not cause any significant toxicity except in three patients who developed transient thrombocytopenia which resolved after a short period of HU cessation.

Though, present study was done on a small number of patients within a short time period, our results indicate that hydroxyurea significantly increases fetal hemoglobin levels and total hemoglobin after a duration of 3 months and 6 months respectively. The drug also reduces the number of transfusions and increases the interval between two transfusions significantly. No significant adverse effects to the HU therapy were observed at the dose used, i.e. $13.70 \pm 2.28 \mathrm{mg} / \mathrm{kg} / \mathrm{d}$ over 1 year of study period. Further studies will be required to evaluate the long term toxicity and benefits to the patients. Although desirable but genetic profile of patients under present study could not be done due to nonavailability of genetic diagnostic facilities in our institute, so analysis of prediction of effectiveness of HU therapy in relation to genotype could not be carried out.

In conclusion we can say from the present study that $\mathrm{HU}$ initially increases $\mathrm{HbF}$ levels followed by increase in $\mathrm{Hb}$, thus leading to decreased number of transfusions which are to be given at less frequent intervals. Thus from present study we can conclude that HU therapy increases total hemoglobin levels sufficiently to decrease the need for transfusions in patients with thalassemia major. Hydroxyurea can be used for the treatment of transfusion dependent thalassemia patients as an effective adjunct to regular transfusion regimen and cost and side effects can be reduced significantly. Analysis of prediction of effectiveness of $\mathrm{HU}$ therapy in relation to genotype could not be carried out, may need further studies for the same.

\section{ACKNOWLEDGEMENT}

Mr. Jasbir Singh, lecturer in Department of Pharmacology for his help in dispensing the drug for the patients, all our patients and their guardians and the staff members of thalassemia day care center.

\section{REFERENCES}

1. Lokeshwar MR, Shah N, Kanakia S, et al. Thalassemia. In: Parthasarathy A ed. IAP textbook of Pediatrics. New Delhi; JAYPEE Publication 4th ed. 2009. p.794-815.

2. Marwah RK, Lal A. Present status of hemoglobinopathies in India. Indian Pediatrics 1994;31:267-71.

3. Rund D, Rachmilenitz E. Beta-thalassemia. N Eng J Med 2005;353:1135-46.

4. Thein SL, Wainscoat JS, Sampietro M. Association of thalassemia intermedia with beta globin gene haplotype. Br J Haematol 1987;65:367-371.

5. Rodgers GP, Dover GJ, Noguchi CT, et al. Haematological responses of patients with sickle cell disease to treatment with hydroxyurea. $\mathrm{N}$ Engl J Med 1990;322:1037-1045. 
6. Zeng YT, Huang SZ, Ren ZR, et al. Hydroxyurea therapy in b-thalassaemia intermedia: improvement in haematological parameters due to enhanced b-globin synthesis. Br J Haematol 1995; 90:557-563.

7. Bradai M, Pissard S, Abad MT, et al. Decreased transfusion needs to be associated with hydroxyurea therapy in Algerian patients with thalassemia major or intermedia. Transfusion 2007;47(10):1830-36.

8. US Pharmacopeial Convention. Ch. 905 Uniformity of dosage units. The National Formulary, 30 th rev. 2007. Rockville, MD, p. 378.

9. Charache S, Terrin ML, Moore RD, et al. Effects of hydroxyurea on the frequency of painful crises in sickle cell anemia. Investigators of the Multicenter Study of Hydroxyurea in Sickle Cell Anemia. N Engl J Med 1995;332:1317-22.

10. Zimmerman S, Schultz W, Davis J, et al. Sustained longterm hematological efficacy of hydroxyurea at maximum tolerated dose in children with sickle cell disease. Blood 2004;103:2039-45.

11. Yavarian M, Karimi M, Bakker E, et al. Response to hydroxyurea treatment in Iranian transfusiondependent beta-thalassemia patients. Haematologica. 2004;89(10):1172-8.

12. Dixit A, Chatterjee TC, Mishra P, et al. Hydroxyurea in thalassemia intermedia-a promising therapy. Ann of Hematol 2005;12:441-6.
13. Ansari SH, Shambi TS, Siddiqui FJ. Efficacy of hydroxyurea in reduction of packed red cell transfusion requirement among children having beta-thalassemia major: Karachi HU Trial. J Pediatrics Hemato Oncol 2007;29(11):729-30.

14. Kosaryan M, Koorosh VK, Karami $\mathrm{H}$, et al. Effect of hydroxyurea on thalassemia major and thalassemia intermedia in Iranian patients. Pak J Med Sci 2009;25(1):74-78.

15. Hoppe C, Vichinsky E, Lewis B, et al. Hydroxyurea and sodium phenylbutyrate therapy in thalassemia intermedia. Am J Hematol 1999;62:221-7.

16. Zamani F, Shakeri R, Eslami SM, et al. Hydroxyurea therapy in 49 patients with major beta-thalassemia. Arch Iranian Med 2009;12(3):295-97.

17. Suthat F, Nappadol S, Pranee W, et al. Hydroxyurea increases hemoglobin $F$ levels and improves the effectiveness of erythropoiesis in $\beta$ thalassemia/hemoglobin E Disease. Blood 1996;87(3):887-92.

18. Sachdeva A, Khanna K, Verma CP, et al. Hydroxyurea and termination of transfusion therapy in transfusion dependent thalassemics. In: The American Society of Hematology Annual Meeting 2002, Detroit, USA.

19. Bradai M, Lamraoui F, Skopinski L, et al. Hydroxyurea can eliminate transfusion requirements in children with transfusion dependent beta-thalassemia. Blood 2003;102:1529-30. 